\title{
Coexistence of papillary thyroid cancer with Hashimoto thyroiditis
}

\author{
Aleksander Konturek • Marcin Barczyński • \\ Wojciech Wierzchowski • Malgorzata Stopa • \\ Wojciech Nowak
}

Received: 1 July 2012 / Accepted: 15 October 2012 / Published online: 26 October 2012

(C) The Author(s) 2012. This article is published with open access at Springerlink.com

\begin{abstract}
Aims Conflicting data have been reported with regard to Hashimoto thyroiditis (HT) and risk of malignancy. The aim of this study was to evaluate coexistence of papillary thyroid cancer (PTC) with HT.

Patients and methods This is a retrospective cohort study in which HT was diagnosed in $452(\mathrm{~F} / \mathrm{M}$ ratio $=405: 47$, median age $53.5 \pm 12.1$ years) of 7,545 patients qualified for thyroidectomy throughout the years 2002 to 2010 . Pathological reports were reviewed to identify prevalence of PTC in HT vs. non-HT patients.

Results PTC was diagnosed in 106 of 452 (23.5\%) HT patients vs. 530 of 7,093 (7.5\%) non-HT patients $(p<$ $0.001)$. Metastases to level VI lymph nodes were observed in 81 of $106(76.4 \%)$ patients with PTC in HT vs. 121 of 530 $(22.8 \%)$ patients with PTC in non-HT disease $(p<0.001)$.

Conclusions HT was associated with a threefold increase of PTC prevalence as compared to other non-HT thyroid diseases, and the spread of PTC to level VI lymph nodes was four times more frequent in HT than in non-HT patients.
\end{abstract}

Keywords Hashimoto thyroiditis · Papillary thyroid carcinoma $\cdot$ Benign thyroid disease

The study was presented at the 5 th Biennial Congress of ESES in Gothenburg, Sweden, May 24-26, 2012.

A. Konturek $(\bowtie) \cdot$ M. Barczyński $\cdot$ M. Stopa $\cdot$ W. Nowak

Department of Endocrine Surgery, 3rd Chair of General Surgery, Jagiellonian University Medical College,

37 Prądnicka Street,

31-202 Krakow, Poland

e-mail: okont@mp.pl

W. Wierzchowski

Department of Pathology,

Jagiellonian University Medical College,

16 Grzegorzecka Street,

31-531 Krakow, Poland

\section{Introduction}

Autoimmune thyroid disease known as Hashimoto thyroiditis (HT) is one of special forms of chronic thyroiditis and the most common non-iatrogenic cause of hypothyroidism. The condition is definitely more prevalent in female population $(\mathrm{M} / \mathrm{F}$ ratio of $1: 10,1: 20)$, is seen in each age group, and may also affect children and adolescents. Its unclear etiopathogenesis strongly indicates an autoimmune background, associated with T-helper lymphocyte (CD4+) activation by class II human leukocyte antigen system cells (MHC class II: HLA-DR3, HLA-DR4, HLA-DR5). On the one hand, the cells recruit cytotoxic lymphocytes $\left(\mathrm{T}_{\mathrm{c}}, \mathrm{CD} 8\right.$ + ), thus facilitating a release of cytokines that damage thyroid follicular cells and, on the other hand, activating B lymphocytes; they facilitate production of specific antimicrosomal, anti-thyroglobulin, or anti-TSH receptor antibodies. Described for the first time in 1912, the disease may have two distinct histological forms: atrophic and nodular. Clinically, in the majority of cases, it is characterized by hypothyroidism, although in a small number of patients, it may be preceded by symptoms of hyperthyroidism. The association between coexistence of Hashimoto thyroiditis and papillary thyroid cancer (PTC) was first described by Dailey et al. in 1955. Since that time, attempts have been made at elucidation of this phenomenon. The objective of the present paper was to demonstrate coexistence of HT with an autoimmune background with highly differentiated thyroid cancer and to attempt to determine assumptions for further therapeutic management and prognosis in patients operated on for Hashimoto thyroiditis and papillary thyroid cancer.

An early detection of lesions, a careful selection of a surgical strategy in a referral center, target-based adjuvant therapy, and treatment monitoring may have a significant impact on improvement of therapeutic outcomes and quality of life in patients with the disease $[1,2]$. 


\section{Materials and methods}

A retrospective analysis included 452 patients diagnosed with Hashimoto thyroiditis and coexisting papillary thyroid cancer selected from among 7,545 patients treated surgically in a single clinical referral center in the years 2002-2010. The mean age of the investigated group was $53.5 \pm 12.1$ years and the F/M ratio was 405:47. The demographics of the investigated group are presented in Table 1. Assessment of the clinical stage was based on the seventh edition of the TNM system (2010), while histopathology results were classified based on a reanalysis of pathology reports pertaining to materials stored in the Histology Department Records. The diagnosis of Hashimoto thyroiditis was defined as the presence of lymphocytic infiltrations in the thyroid parenchyma and stroma, with formation of reaction centers and lymphoid nodules and presence of oxyphilic cells. The lymph nodes were characterized by nonspecific reactive lesions. High levels of anti-peroxidase antibodies confirmed the diagnosis. The extent of primary surgery performed in the presented group included total thyroidectomy with central compartment lymph node dissection in $91 \%$ patients; in the remaining cases, bilateral subtotal thyroid lobectomies were done. Histopathology confirming cancer presence constituted an indication for total resection of the residual thyroid tissue.

All the patients qualified for surgical treatment were subjected to thyroid ultrasonography, determinations of free thyroid hormones (fT4, fT3), thyrotropic hormone (TSH), as well as anti-thyroid peroxidase (TPO) and anti-thyroglobulin (TG) antibodies. The inclusion criteria for surgery in the HT group included nodular lesions of the thyroid detected by ultrasound as hypoechoic or hyperechoic nodular pattern at least $5 \mathrm{~mm}$ in diameter, identification of a perinodular hypoechogenic or hyperechogenic halo, and the presence of an anechoic lesion

Table 1 Demographic characteristics of 7,545 patients analyzed in this study

\begin{tabular}{lllc}
\hline & HT $(n=452)$ & $\begin{array}{l}\text { Non-HT } \\
(n=7,093)\end{array}$ & $p$ value \\
\hline Gender ratio (M/F) & $47: 405$ & $667: 6,426$ & 0.484 \\
Average age (years) & $53.5 \pm 12.1$ & $52.3 \pm 15.5$ & 0.739 \\
$\begin{array}{l}\text { Preoperative thyroid volume } \\
\quad \text { in ml (by ultrasound), }\end{array}$ & $22.1 \pm 18.2$ & $96.2 \pm 40.4$ & $<0.001^{\text {a }}$ \\
$\begin{array}{l}\text { mean } \pm \text { SD } \\
\text { Preoperative diagnosis, } n(\%)\end{array}$ & & & \\
$\begin{array}{l}\text { Benign thyroid disease (BTD) } \\
\text { Positive FNAB for PTC }\end{array}$ & $321(93.1)$ & $6,881(97.0)$ & $<0.001$ \\
\hline
\end{tabular}

$B T D$ multinodular nontoxic goiter, multinodular toxic goiter, Graves disease, and Hashimoto disease, FNAB fine-needle aspiration biopsy, PTC papillary thyroid cancer

${ }^{\mathrm{a}} t$ test was used for statistical analysis with a reinforced posterior wall. A repeated analysis of fineneedle aspiration biopsy (FNAB) results based on the Bethesda 2009 classification showed that in the test results, the predominating lesions were these that today would be classified as groups III and IV of the above classification system. In the non-HT group, surgical treatment was indicated in case of suspicious lesions detected by FNAB (groups IIIVI according to Bethesda 2009), symptoms of tracheal and surrounding tissue compression, multinodular toxic goiter, and Graves' disease. Prior to surgical treatment, all the patients presenting with clinical and biochemical hypothyreosis received levothyroxine substitution. The mean follow-up time in the analyzed group was $4.3 \pm 2.1$ years. In the first postoperative day, indirect laryngoscopy was performed in all the patients and their calcium levels were determined; hypocalcemia was assumed at total calcium levels below $2.0 \mathrm{mmol} /$ 1. Following thyroidectomy and the diagnosis of differentiated thyroid carcinoma, a uniform model of therapeutic management was employed in all the patients; the model consisted of radioiodine adjuvant treatment in case of tumors with a diameter of $>10 \mathrm{~mm}$, administration of L-thyroxine (at a dose ensuring the suppression level for TSH range of $0.1-$ $0.3 \mathrm{mU} / \mathrm{l}$ ), and strict periodic follow-up determination of hormones and anti-TG.

Statistical analysis for normally distributed variables employed the Student's $t$ test in comparisons, while the remaining variables were analyzed using the $\chi^{2}$ test. When the test assumptions were not fulfilled, comparisons were based on the so-called Fisher's exact test. The criterion of including a variable into the model was $p<0.05$.

\section{Results}

In the analyzed group of 452 patients with Hashimoto thyroiditis, $106(23.5 \%)$ cases of papillary thyroid cancer (HT-PTC) were detected as compared to 530 (7.5\%) cancer patients in the group of 7,093 individuals (non-HT-PTC) without diagnosed autoimmune disease. The values are statistically significant $(p<0.001)$. Both the analyzed groups showed a similar ratio of males to females (1:9 in HT-PTC group vs. 1:10 in non-HT-PTC group) and a similar mean age of the patients $(53.5 \pm 12.1$ years in HT-PTC group vs. $52.3 \pm 15.5$ years in non-HT-PTC group). A statistically significant difference was observed in preoperative goiter volume as determined by ultrasonography $(22.1 \pm 18.2 \mathrm{ml}$ in HT-PTC group vs. $96.2 \pm 40.4 \mathrm{ml}$ in non-HT-PTC group, $p<$ $0.001)$. FNAB was performed in all the patients with nodular lesions above $5 \mathrm{~mm}$ in diameter, but in the HT-PTC group, only $31(29.2 \%)$ of 106 HT-PTC subjects had thyroid tumor diagnosed preoperatively. In the remaining cases, cytological material did not raise any suspicions of neoplastic process. In FNAB smears, oxyphilic cells with 
lymphocytes and macrophages predominated (Table 1). In eight $(12.3 \%)$ patients $\left(\mathrm{pT}_{1 \mathrm{a}}=65\right)$ with a nodule of $8_{-}$ $10 \mathrm{~mm}$ in size, FNAB confirmed thyroid microcarcinoma. In one case, in a 4-mm nodule, a focus of papillary thyroid carcinoma was detected preoperatively. The above lesions were seen in females in a lower age range as compared to the entire group (16-46 years).

However, prevalence of suspicious FNAB cytology in non-HT-PTC group was significantly higher and equal to $212(40.0 \%)$ of 530 patients $(p<0.001) \cdot \mathrm{pT}_{1 \mathrm{a}}$ stage papillary thyroid carcinoma predominated in patients with Hashimoto thyroiditis as compared to the remaining analyzed patients. The values were 65 (14.4\%) in HT-PTC vs. $301(4.24 \%)$ in non-HT-PTC $(p<0.001)$. A similar distribution was observed in the group with the multifocal form of papillary thyroid cancer $\left(\mathrm{pT}_{1 \mathrm{~m}}\right): 22(4.9 \%)$ in HT-PTC vs. 119 $(1.7 \%)$ in non-HT-PTC, although the differences were not significant. Multifocality was defined as the presence of $\geq 2$ cancer foci in one or both thyroid lobes. A statistically significant difference was noted with respect to nodal metastases in the central cervical compartment (compartment VI). Such metastases were observed in 81 of $106(76.4 \%)$ patients with HT-PTC and only in 121 of 530 (22.8\%) nonHT-PTC patients $(p<0.001)$. The metastases were particularly common in $\mathrm{pT}_{1 \mathrm{a}}$ papillary thyroid cancer: $46(43.4 \%)$ in HT-PTC vs. 29 (5.47 \%) in non-HT-PTC. The mean size of the largest single focus in the HT-PTC group was $7.61 \pm$ 5.78; nevertheless, in a high number of patients $\left(\mathrm{pT}_{1 \mathrm{~m}}\right.$ : HT$\mathrm{PTC}=22(4.9 \%)$ ), the lesions were $2-3 \mathrm{~mm}$ in size and were noted in both thyroid lobes (Table 2). In HT patients, preparations of cervical compartment lymph nodes showed a higher number of dissected lymph nodes and a higher number of metastatically involved lymph nodes as compared to non-HT patients (Table 2).

No significant differences were observed between HT-PTC patients and non-HT-PTC patients (Table 3) with regard to the prevalence of complications following thyroidectomy.

\section{Discussion}

An unambiguous association between papillary thyroid cancer and Hashimoto thyroiditis was demonstrated for the first time by Dailey et al. in 1955 [1]. According to abundant data from the literature on the subject [2-9, 17, 21-24, 34, 37, 38] and a meta-analysis performed by Singh et al. [2], PTC coexisted with Hashimoto thyroiditis 2.8 more frequently and its prevalence investigated in patient groups as reported in various articles ranged from 0.5 to $30 \%$ (Table 4). PTC was also observed to occur almost twice as often as other types of thyroid cancer. In the presently analyzed material, in as many as $23.5 \%$ patients, papillary thyroid cancer arose from lesions characterized as chronic autoimmune thyroiditis. This
Table 2 Final histopathology diagnosis after thyroidectomy in 7,545 patients involved in this study

$$
\text { HT }(n=452) \begin{aligned}
& \text { Non-HT } \\
& (n=7,093)
\end{aligned} \quad p \text { value }
$$

\begin{tabular}{|c|c|c|c|}
\hline \multicolumn{4}{|l|}{ Papillary thyroid cancer, no. (\%) } \\
\hline Total & $106(23.5)$ & $530(7.5)$ & $<0.001$ \\
\hline \multicolumn{4}{|l|}{ TNM classification } \\
\hline \multicolumn{4}{|l|}{ Primary tumor } \\
\hline $\mathrm{pT}_{1 \mathrm{a}} \mathrm{N}_{\mathrm{x}} \mathrm{M}_{\mathrm{x}}$ & $65(61.3)$ & $301(56.7)$ & $<0.001$ \\
\hline $\mathrm{pT}_{1 \mathrm{~b}} \mathrm{~N}_{\mathrm{x}} \mathrm{M}_{\mathrm{x}}$ & $18(17.0)$ & $45(8.4)$ & $<0.001$ \\
\hline $\mathrm{pT}_{1 \mathrm{~m}} \mathrm{~N}_{\mathrm{x}} \mathrm{M}_{\mathrm{x}}$ & $22(20.8)$ & $119(22.4)$ & 0.01 \\
\hline $\mathrm{pT}_{2} \mathrm{~N}_{\mathrm{x}} \mathrm{M}_{\mathrm{x}}$ & $1(0.9)$ & $66(12.5)$ & $<0.001$ \\
\hline \multicolumn{4}{|l|}{ Regional lymph nodes } \\
\hline $\mathrm{pT}_{1 \mathrm{a}} \mathrm{N}_{1 \mathrm{a}} \mathrm{M}_{\mathrm{x}}$ & $46(43.4)$ & $29(5.5)$ & $<0.001$ \\
\hline $\mathrm{pT}_{1 \mathrm{~b}} \mathrm{~N}_{1 \mathrm{a}} \mathrm{M}_{\mathrm{x}}$ & $16(15.1)$ & $41(7.7)$ & $<0.001$ \\
\hline $\mathrm{pT}_{1 \mathrm{~m}} \mathrm{~N}_{1 \mathrm{a}} \mathrm{M}_{\mathrm{x}}$ & $18(17.0)$ & $43(8.1)$ & $<0.001$ \\
\hline $\mathrm{pT}_{2} \mathrm{~N}_{1 \mathrm{a}} \mathrm{M}_{\mathrm{x}}$ & $1(0.9)$ & $8(1.5)$ & 0.07 \\
\hline $\begin{array}{l}\text { Diameter of the largest foci in } \mathrm{mm} \\
(\text { mean } \pm \mathrm{SD})\end{array}$ & $7.6 \pm 5.8$ & $9.4 \pm 6.9$ & 0.01 \\
\hline $\begin{array}{l}\text { Number of removed lymph nodes } \\
\text { within level VI (mean } \pm \text { SD) }\end{array}$ & $12.7 \pm 3.7$ & $6.5 \pm 2.4$ & $<0.001$ \\
\hline $\begin{array}{l}\text { Number of macrometastatic lymph } \\
\text { nodes }(\text { mean } \pm \text { SD) }\end{array}$ & $6.4 \pm 2.7$ & $2.1 \pm 1.0$ & $<0.001$ \\
\hline
\end{tabular}

percentage constituted a threefold increase of the number of PTC cases in the population of Hashimoto thyroiditis patients as compared to the overall number of individuals with papillary thyroid cancer in the investigated group (non-HT-PTC= 530 patients). The above quoted data from literature and the results of our observations clearly point to an increase in neoplastic disease prevalence in patients suffering from an autoimmune disease. To date, there are no unambiguous indications for determining whether an autoimmune disease

Table 3 Complications after thyroidectomy in 636 patients involved in this study

\begin{tabular}{llll}
\hline & $\begin{array}{l}\text { PTC in HT } \\
(n=106)\end{array}$ & $\begin{array}{l}\text { PTC in non- } \\
\text { HT }(n=530)\end{array}$ & \\
\hline $\begin{array}{l}\text { Parathyroid found in pathological } \\
\text { report, no. (\%) }\end{array}$ & $5(4.7)$ & $27(5.1)$ & 0.871 \\
$\begin{array}{l}\text { Hypoparathyroidism after operation, no. (\%) } \\
\text { Total }\end{array}$ & & \\
Transient & $47(44.3)$ & $209(39.4)$ & 0.347 \\
Permanent & $45(42.4)$ & $197(37.2)$ & 0.306 \\
Unilateral RLN injury, no. (\%) & & $12(2.3)$ & 0.809 \\
Total & $12(5.7)$ & $55(5.2)$ & 0.766 \\
Transient & $9(4.2)$ & $41(3.9)$ & 0.792 \\
Permanent & $3(1.4)$ & $14(1.3)$ & 0.909 \\
\hline
\end{tabular}

Calculation was made for nerves at risk, not for patients (there were 212 nerves at risk in PTC in HT group and 1,060 nerves at risk in PTC in non-HT group). Chi-squared test was employed for all values 
Table 4 Coexistence Hashimoto thyroiditis with papillary thyroid cancer

\begin{tabular}{lll}
\hline Authors & $\begin{array}{l}\text { Patient included } \\
\text { in the study }\end{array}$ & $\begin{array}{l}\text { HT with PTC, } \\
n(\%)\end{array}$ \\
\hline Dailey at al. [1] & 278 with PTC & $35(12.6)$ \\
Singh et al. [2] & 388 with PTC & $57(15.0)$ \\
Chesky VE et al. [3] & 432 with HT & $48(11.1)$ \\
Ott et al. [6] & 161 with TC & $61(38.0)$ \\
Eisenberg et al. [7] & 120 with TC & $13(10.8)$ \\
Sclafani et al. [8] & 48 with HT & $8(17.0)$ \\
Schäffler et al. [9] & 153 with TC & $10(6.5)$ \\
Matesa-Anić et al. [17] & 10,508 FNAB & $42(0.5)$ \\
Cipolla et al. [20] & 71 with PTC & $19(26.7)$ \\
Pisanu et al. [21] & 344 with PTC & $33(9.6)$ \\
Kebebew et al. [23] & 136 with PTC & $41(30)$ \\
Matsubayashi et al. [24] & 95 with PTC & $36(37.9)$ \\
Yoon et al. [34] & 195 with PTC & $56(28.7)$ \\
Paulson et al. [37] & 139 with PTC & $61(43.8)$ \\
Repplinger et al. [38] & 217 with HT & $63(29)$ \\
\hline
\end{tabular}

Literature review was used in this study

$H T$ Hashimoto thyroiditis, TC thyroid cancer, PTC papillary thyroid cancer, $F N A B$ fine-needle aspiration biopsy

predisposes the patient to develop cancer or whether in the course of carcinogenesis-associated cellular transformations, there occurs a change in autoimmune responses that would facilitate the development of such a disease. Segal et al. [10] suggest that Hashimoto thyroiditis does not determine but rather delays cancer development, while circulating antibodies may constitute a significant factor preventing tumor development and nodal metastases. This thesis is in opposition to the investigations by Di Pasquale et al. [11] that suggest the very autoimmune background in all cases of cancer coexisting with Hashimoto thyroiditis. The hypothesis assumes an increased genetic predisposition to the development of neoplastic lesions. Information on molecular factors that determine initiation, promotion, and progression of thyroid cancers has been the subject matter of numerous investigations in recent years. In keeping with the theory of multistage carcinogenesis, various phenotypic variants of thyroid tumors may develop through genetic defects of the signaling cascade, via activation and inactivation of oncogenes and serial mutations. Presently, the best known form of such alterations in papillary thyroid cancer is the concept of oncogenic RET/PTC1 and RET/PTC3 sequences that are also present in chronic lymphocytic thyroiditis, but with no clinical manifestation of lesions in the thyroid parenchyma $[12,13]$. The RET/PTC1 mutation was detected by Sheils et al. in as many as $95 \%$ of investigated patients with Hashimoto thyroiditis [14]. In the aforementioned reports, the authors suggest that the presence of mutations involving the RET/PTC oncogenes may be an early molecular indicator of papillary thyroid microcarcinoma lesions. Recent experience with the use of PCR in cytological diagnostic management of material obtained by FNAB may be of importance in detecting neoplastic lesions before they become clinically manifested [15]. The significance of molecular studies as an element of cytological diagnostics of thyroid lesions is confirmed by considerable differences in papillary thyroid cancer diagnoses in biopsy materials. According to literature [2, 16-21], histologyconfirmed diagnoses of papillary thyroid cancer fall within an extremely wide range from $0.4 \%$ in the reports by Matesa et al. [17] to $92 \%$ in keeping with the data provided by Singh et al. $[2,21]$. In our material, in 31 of $452(6.9 \%)$ HT patients, confirmation of the diagnosis of papillary thyroid carcinoma in material collected by targeted fine-needle aspiration biopsy was achieved, which accounted only for $29.2 \%$ of all HT-PTC diagnoses established based on final histopathology. The reason behind such significant differences lies in difficulties in defining lesions that require cytological diagnostics. In all nodular, localized lesions situated within the thyroid parenchyma, specificity and sensitivity were high, ranking between 87 and $92 \%$. In atrophic Hashimoto thyroiditis with increased tissue density, false-negative results predominated. This happened due to lymphocytic infiltrations with reaction center formation both in the thyroid tissue and around the suspected primary focus. Some authors believe the presence of such infiltrations to be a factor predisposing to tumor development $[2,22]$, while others regard it as a response of the body to neoplastic disease, hence the potentially better prognosis in this group of patients [2, 9, 23-25]. Kebebew et al. [23] firmly indicate that the presence of chronic lymphocytic thyroiditis in patients with papillary thyroid cancer improves the prognosis. On the other hand, it cannot be at the same time an independent prognostic factor indicating a lower number of recurrences or the presence of nodal metastases. This common transformation path of thyroid cells in papillary thyroid cancer and Hashimoto thyroiditis has been also attempted to be explained by similarities in activation of the metabolic cycle of tyrosine kinases (PI3k/Akt pathway) and overexpression of $\mathrm{p} 63$ protein that leads to apoptosis inhibition [26, 27].

Another extremely important element that plays a role in clinical assessment of papillary thyroid cancer is the size of the primary focus. Tumors up to $10 \mathrm{~mm}$ in diameter are characterized by a favorable prognosis, although they may demonstrate all specific properties of a malignancy, with possible nodal metastasizing, capsular infiltration, or multifocal growth in the thyroid tissue. Bradley et al. [28] analyzed a group of accidentally detected forms of papillary thyroid cancer $(687$ patients, 81 IPTC (12\%)) and confirmed this tumor form in as many as $21(28 \%)$ patients of 74 individuals with Hashimoto thyroiditis. The primary focus size did not exceed $7 \mathrm{~mm}$. (mean $2.8 \pm 1.7 \mathrm{~mm}$ ). In the present analysis, although the mean focus size was larger as compared to the abovementioned values, it did not exceed $10 \mathrm{~mm}$ in diameter, thus 
providing the basis for microcarcinoma diagnosis. In the analyzed material, microcarcinomas were markedly predominant $(65$ cases $=61.3 \%)$. Of significance is also a relatively high number $(22=20.8 \%)$ of patients with multifocal PTC form and with foci with the diameter starting from 2 to $5 \mathrm{~mm}$. Based on the analysis, one may thus surmise that coexistence of an autoimmune disease and papillary thyroid cancer did not limit the number of primary foci and affected their size only $[29,30]$. The above data have been quite extensively confirmed in the literature on the subject. Numerous authors are inclined to believe that coexistence of lymphocytic infiltrations, positive history of thyroid autoimmune diseases, or significantly high antibody levels (anti-TPO, anti-TG) prior to surgery had a significant impact on prognosis improvement. Although there have been voiced opinions that such factors did not affect mortality rates, they undoubtedly determined early initiation of targeted therapy [30].

Tumor grading determined by the degree of capsular infiltration and nodal metastasizing allows for selecting patients with a poor prognosis. As it has been mentioned previously, papillary thyroid cancer is generally characterized by a good prognosis. This is particularly true in patients with highly differentiated $\mathrm{pT}_{1 \mathrm{a}}$ cancers that do not exceed $10 \mathrm{~mm}$ in diameter. It should be noted, however, that even these forms show a fairly high ability to metastasize. In their analysis of 203 patients with papillary thyroid microcarcinoma, So et al. found nodal metastases in as many as $24.6 \%$ of subjects, multifocal cancer in $31 \%$, and capsular infiltrations in $20.7 \%$ of their surgical patients [31]. Similar observations were made by Mercante et al. and Cho et al. [32, 33], who emphasized that the size of the primary focus did not play a role in the presence or absence of nodal metastases or capsular infiltrations. Is there, then, any difference in tumor morphology, ability to metastasize, and prognosis in patients with papillary thyroid cancer and Hashimoto thyroiditis?

In the entire presently analyzed material, the presence of central compartment lymph node metastases was significantly higher in patients with cancer and Hashimoto thyroiditis (PTCHT $=81(76.4 \%)$ vs. non-HT-PTC $=121(22.8 \%))$. According to numerous reports, metastatic foci in cervical lymph nodes accompany both "clear" cancer forms and tumors presenting with symptoms of chronic lymphocytic thyroiditis. The degree of nodal involvement - differently reported in various publications - ranged from 7 to $49 \%$ [34-36]. In one of the recent articles, Paulson et al. [37] suggest that a lower number of nodal metastases to the central compartment are a result of a coexisting autoimmune disease and the protective role it plays in neoplastic spreads beyond the primary focus area.

Based on our observations of both groups of patients, a conclusion has been formulated that concomitant Hashimoto's thyroiditis and papillary thyroid carcinoma are more common phenomena than previously believed, since they are observed in approximately $20 \%$ of all cases of this cancer type.
According to data from the literature on the subject, it is significantly more common among women from younger age groups, is characterized by lesions with a small diameter of the primary focus, and, at times, has a multifocal form, but the prognosis is statistically more favorable as compared to other patient groups [20,38]. Improved ultrasound techniques, higher availability of examinations, and higher awareness of patients today allow for early institution of appropriate treatment. The above-described observations of the present authors, as well as data from world literature, indicate a need for further immunological and genetic investigations aiming at understanding the nature of a protective role of coexistence of an autoimmune disease and thyroid cancer. It should be remembered, however, that the continuously low number of patients, high costs of genetic probes, and ambiguous diagnostic protocol limit the use of such observations in clinical practice. Hence, in view of the high percentage of PTC in HT and incidence of complications following total thyroidectomies that is comparable to that observed in operations performed in patients with nonneoplastic goiter [39-41], the optimum strategy of surgical treatment of Hashimoto thyroiditis in such patients should include total thyroidectomy and preventive central compartment lymphadenectomy, which is of importance in assessing tumor stage and determining recommendations for further adjuvant therapy. Total thyroidectomy along with excision of central compartment lymph nodes may result in damaging recurrent laryngeal nerves and accidental excision of inferior parathyroids glands. Nevertheless, the incidence of such complications in referral centers is low.

The literature on the subject increasingly more often presents reports stating that primary total thyroidectomy allows not only for treating the neoplastic disease already diagnosed based on the FNAB result but also contributes to a decrease in reoperation rate due to postoperative diagnosis of thyroid cancer. Analyzing this aspect, we may say that primary total thyroidectomy also limits the number of permanent complications, which in a significant percentage of cases pose a considerable threat in the course of reoperation. In our opinion, the above-described rationale provides a foundation for considering radical surgical treatment in cases of nodular lesions being present in immunologically altered thyroid gland.

\section{Conflicts of interest None.}

Open Access This article is distributed under the terms of the Creative Commons Attribution License which permits any use, distribution, and reproduction in any medium, provided the original author(s) and the source are credited.

\section{References}

1. Dailey ME, Lindsay S, Skahen R (1955) Relation of thyroid neoplasms to Hashimoto's disease of the thyroid gland. Arch Surg 70:291-297 
2. Singh B, Shaha AR, Trivedi H, Carew JF, Poluri A, Shah JP (1999) Coexistent Hashimoto's thyroiditis with papillary thyroid carcinoma: impact on presentation, management, and outcome. Surgery 126:1070-6

3. Chesky VE, Hellwig CA, Welch JW (1961) Cancer of the thyroid associated with Hashimoto's disease: an analysis of forty eight cases. Am Surg 28:678-85

4. Crile G, Fisher ER (1953) Simultaneous occurrence of thyroiditis and papillary carcinoma. Report of two cases. Cancer 6:57-62

5. Crile G (1978) Struma lymphomatosa and carcinoma of the thyroid. Surg Gynecol Obstet 147:350-2

6. Ott RA, McCall AR, McHenry C, Jarosz H, Armin A, Lawrence AM, Paloyan E (1987) The incidence of thyroid carcinoma in Hashimoto's thyroiditis. Am Surg 53(8):442-5

7. Eisenberg BL, Hensley SD (1989) Thyroid cancer with coexistent Hashimoto's thyroiditis. Clinical assessment and management. Arch Surg 124:1045-1047

8. Sclafani AP, Valdes M, Cho H (1993) Hashimoto's thyroiditis and carcinoma of the thyroid: optimal management. Laryngoscope 103:845-849

9. Schäffler A, Palitzsch KD, Seiffarth C, Höhne HM, Riedhammer FJ, Hofstädter F, Schölmerich J, Rüschoff J (1998) Coexistent thyroiditis is associated with lower tumour stage in thyroid carcinoma. Eur J Clin Invest 28:838-844

10. Segal K, Ben-Bassat M, Avraham A, Hard-El G, Sidi J (1985) Hashimoto's thyroiditis and carcinoma of the thyroid gland. Intl Surg 70:205-9

11. Di Pasquale M, Rothstein JL, Palazzo JP (2001) Pathologic features of Hashimoto's-associated papillary thyroid carcinomas. Human Pathol 32:24-30

12. Wirtschafter A, Schmidt R, Rosen D, Kundu N, Santoro M, Fusco A, Multhaupt H, Atkins J, Rosen MR, Keane W, Rothstein JL (1997) Expression of the RET/PTC fusion gene as a marker of papillary carcinoma in Hashimoto's thyroiditis. Laryngoscope 107:95-100

13. Arif S, Blanes A, Diaz-Cano SJ (2002) Hashimoto's thyroiditis shares features with early papillary thyroid carcinoma. Histopathology 41:357-62

14. Sheils OM, O’Leary JJ, Uhlmann V, Lüttich K, Sweeney EC (2000) RET/PTC-1 activation in Hashimoto thyroiditis. J Surg Pathol 8:185-189

15. Cyniak-Magierska A, Wojciechowska-Durczyńska K, KrawczykRusiecka K, Zygmunt A, Lewiński A (2011) Assessment of RET/ PTC1 and RET/PTC3 rearrangements in fine-needle aspiration biopsy specimens collected from patients with Hashimoto's thyroiditis. Thyroid Res 10(1):4-5

16. Su DH, Liao KM, Hsiao YL, Chang TC (2004) Determining when to operate on patients with Hashimoto's thyroiditis with nodular lesions: the role of ultrasound-guided fine needle aspiration cytology. Acta Cytol 48:622-9

17. Matesa-Anić D, Matesa N, Dabelić N, Kusić Z (2009) Coexistence of papillary carcinoma and Hashimoto's thyroiditis. Acta Clin Croat 48(1):9-12

18. Kumarasinghe MP, De Silva S (1999) Pitfalls in cytological diagnosis of autoimmune thyroiditis. Pathology 31:1-7

19. Moon HJ, Kim EK, Kim MJ, Kwak JY (2009) Lymphocytic thyroiditis on fine-needle aspiration biopsy of focal thyroid nodules: approach to management. AJR Am J Roentgenol 193:345-9

20. Cipolla C, Sandonato L, Graceffa G, Fricano S, Torcivia A, Vieni S, Latteri S, Latteri MA (2005) Hashimoto thyroiditis coexistent with papillary thyroid carcinoma. Am Surg 71(10):874-8

21. Pisanu A, Piu S, Cois A, Uccheddu A (2003) Coexisting Hashimoto's thyroiditis with differentiated thyroid cancer and benign thyroid diseases: indications for thyroidectomy. Chir Ital 55:365-72

22. Okayasu I, Fujiwara M, Hara Y, Tanaka Y, Rose NR (1995) Association of chronic lymphocytic thyroiditis and thyroid papillary carcinoma: a study of surgical cases among Japanese, and white and African Americans. Cancer 76:2312-2318
23. Kebebew E, Treseler PA, Ituarte PH, Clark OH (2001) Coexisting chronic lymphocytic thyroiditis and papillary thyroid cancer revisited. World J Surg 25:632-7

24. Matsubayashi S, Kawai K, Matsumoto Y, Mukuta T, Morita T, Hirai K, Matsuzuka F, Kakudoh K, Kuma K, Tamai H (1995) The correlation between papillary thyroid carcinoma and lymphocytic infiltration in the thyroid gland. J Clin Endocrinol Metab 80:3421-3424

25. Feldt-Rasmussen U, Rasmussen AK (2010) Autoimmunity in differentiated thyroid cancer: significance and related clinical problems. Hormones 9(2):109-17

26. Unger P, Ewart M, Wang BY, Gan L, DS Ko, Burstein DE (2003) Expression of p63 in papillary thyroid carcinoma and in Hashimoto's thyroiditis: a pathobiologic link? Hum Pathol 34:764-769

27. Larson SD, Jackson LN, Riall TS, Uchida T, Thomas RP, Qiu S, Evers BM (2007) Increased incidence of well-differentiated thyroid cancer associated with Hashimoto's thyroiditis and the role of the PI3k/Akt pathway. J A m Coll Surg 204:764-763

28. Bradly DP, Reddy V, Prinz RA, Gattuso P (2009) Incidental papillary carcinoma in patients treated surgically for benign thyroid diseases. Surgery 146:1099-104

29. Siassakos D, Gourgiotis S, Moustafellos P, Dimopoulos N, Hadjiyannakis E (2008) Thyroid microcarcinoma during thyroidectomy. Singapore Med J 49:23-5

30. Souza SL, da Assumpção LVM, Ward LS (2003) Impact of previous thyroid autoimmune diseases on prognosis of patients with well-differentiated thyroid cancer. Thyroid 13(5):491-495

31. So YK, Son YI, Hong SD, Seo MY, Baek CH, Jeong HS et al (2010) Subclinical lymph node metastasis in papillary thyroid microcarcinoma: a study of 551 resections. Surgery 148:526-531

32. Mercante G, Frasoldati A, Pedroni C, Formisano D, Renna L, Piana S, Gardini G, Valcavi R, Barbieri V (2009) Prognostic factors affecting neck lymph node recurrence and distant metastasis in papillary microcarcinoma of the thyroid: results of a study in 445 patients. Thyroid 19(7):707-716

33. Chow SM, Law SC, Chan JK, Au SK, Yau S, Lau WH (2003) Papillary microcarcinoma of the thyroid - prognostic significance of lymph node metastasis and multifocality. Cancer 98:31-40

34. Yoon YH, Kim HJ, Lee JW, Kim HM, Seok B (2012) The clinicopathologic differences in papillary thyroid carcinoma with or without co-existing chronic lymphocytic thyroiditis. European Archives of Oto-Rhino-Laryngology 269(3):1013-1017

35. Cuhna LL, Ward LS (2012) Concurrent lymphocytic thyroiditis is associated to less aggressive papillary thyroid carcinomas. Letter to the Editor. European Archives of Oto-Rhino-Laryngology 269(2):699-700

36. Cuhna LL, Ward LS (2011) Comments on "Well-Differentiated Thyroid Carcinoma with Concomitant Hashimoto's Thyroiditis Present with Less Aggressive Clinical Stage and Low Recurrence". Endocr Pathol 22(3):172-173

37. Paulson LM, Shindo ML, Schuff KG (2012) Role of chronic lymphocytic thyroiditis in central node metastasis of papillary thyroid carcinoma. Otolaryngol Head Neck Surg 147(3):444-9

38. Repplinger D, Bargren A, Zhang YW, Adler JT, Haymart M, Chen H (2008) Is Hashimoto's thyroiditis a risk factor for papillary thyroid cancer? J Surg Res 150:49-52

39. Barczyński M, Konturek A, Stopa M, Cichoń S, Richter P, Nowak W (2011) Total thyroidectomy for benign thyroid disease: is it really worthwhile? Ann Surg 254:724-729

40. Barczyński M, Konturek A, Hubalewska-Dydejczyk A, Gołkowski F, Cichoń S, Nowak W (2010) Five-year follow-up of a randomized clinical trial of total thyroidectomy versus Dunhill operation versus bilateral subtotal thyroidectomy for multinodular nontoxic goiter. World J Surg 34:1203-1213

41. Barczyński M, Konturek A, Hubalewska-Dydejczyk A, Gołkowski F, Nowak W (2012) Randomized clinical trial of bilateral subtotal thyroidectomy versus total thyroidectomy for Graves' disease with a 5-year follow-up. Br J Surg 99:515-522 